\title{
Metacognitive and Meta-Emotional Styles in Patients With Alcohol and the Other Substance Dependence
}

\author{
Okan Ufuk Ipek ${ }^{1, *}$; Kaasim Fatih Yavuz ${ }^{1}$; Sevinc Ulusoy ${ }^{1}$; Oktay Sahin ${ }^{1}$; Erhan Kurt ${ }^{1}$ \\ ${ }^{1}$ Bakirkoy Research and Training Hospital for Psychiatric and Neurological Diseases, Istanbul, Turkey \\ ${ }^{*}$ Corresponding author: Okan Ufuk Ipek, Bakirkoy Research and Training Hospital for Psychiatric and Neurological Diseases, Istanbul, Turkey. Tel: +90-2124091515, Fax: +90-2126605441,
} E-mail:okansey@hotmail.com

Received: November 4, 2014; Revised: December 17, 2014; Accepted: January 5, 2015

Background: Both alcohol and other substances are utilized for emotional and cognitive regulation.

Objectives: The purpose of the present study was to compare metacognitive styles and distress intolerance in patients with alcohol and other substance dependence.

Patients and Methods:According to DSM-IVTR criteria, 45 patients with alcohol dependence(AD), 44 patients with substance dependence (SD), and 43 volunteers without AD or SD (control group) were enrolled. Socio-demographic information form, Distress Tolerance Scale (DTS), and metacognitive questionaire-30 (MCQ-30) were used to evaluate the participants.

Results: Patients with AD had significantly lower "tolerance" subscale and total DTS scores than those with SD and control group $(\mathrm{P}=0.008$ for SD sample and $\mathrm{P}=0.004$ for control group). Patients with SD had significantly higher scores in "appraisal" subscale DTS than control group $(P=0.005)$. Patients of both $A D$ and SD groups had significantly higher scores in "positive beliefs" subscale of MCQ-30 than control group $(\mathrm{P}=0.012$ for $\mathrm{AD}$ group and $\mathrm{P}=0.001$ for $\mathrm{SD}$ group). There was no significant difference between $\mathrm{AD}$ and SD groups in any MCQ-30 subscale and total scores $(\mathrm{P}=0.440)$.

Conclusions: Metacognitive regulation strategies are more considerable prediction than emotional regulation strategies in SD group than in $\mathrm{AD}$ group. Individuals with $\mathrm{AD}$ use alcohol as a means of both cognitive and emotional regulation strategy.

Keywords: Cognition; Emotions; Substance Dependence

\section{Background}

Self-reports and clinical observations suggest that alcohol affects emotion regulation. Many studies patients with alcohol dependence (AD) have comorbid psychiatric disorders, especially mood and anxiety disorders (1-3). There are different studies about regulating emotions with alcohol (4-7). In addition to emotional regulation roles of substance and alcohol, Toneatto (8) reported that substances are used to regulate a wide range of cognitive events, especially unpleasant ones; thus, individuals use substance to regulate unpleasant cognitive events than pleasant ones. Although emotional and cognitive regulation has an important role in alcohol and substance dependence, there is a new issue regarding this phenomenon, i.e. metacognition.

Metacognitive theory and researches propose underlying mechanisms of psychologic abnormalities and ways to treat these abnormalities (9-11). This theory suggests that psychologic dysfunctions are due to some inappropriate thinking patterns, namely, worry and rumination (9-11). In addition, thinking patterns are attentional bias about threat-associated stimulus called threat monitoring. There are additional strategies to react to cogni- tions, i.e., thought suppression and avoidance. All the strategies to deal with threat, self-discrepancies, and the emotion are called the cognitive attentional syndrome (CAS). These strategies constitutes increased amount of negative cognitions. When the components of the CAS are triggered by cognitive and emotional triggers, these strategies constitutes increased amount of negative cognitions (9). This process depends on dysfunctional metacognitions. Metacognition describes knowledge or belief about interpretation, monitoring and control of cognition. Metacognitions are also about internal feedback loops that cause persistent thinking process to achieve a goal $(9,12)$. There are two different content headline of metacognitive belief contributing to CAS, i.e. positive and negative metacognitive beliefs. Positive beliefs are about benefits of rumination, worry, threat monitoring, and avoidance. The negative beliefs have two broad subheadings; one of them is uncontrollability of thoughts and the other is danger of thoughts (9).

Metacognitions are associated with depression (13), procrastination (14), obsessive-compulsive symptoms (15), perceived stress (16), hypochondriasis (17), pathologic post- 
traumatic stress disorder (18), and test anxiety (19). Relatively new researches are about utilizing metacognitive theory in prediction and in determining the association between metacognitions and alcohol or substance use (20-23).

\section{Objectives}

In view of these findings, the purpose of the present study was to compare metacognitive styles and distress intolerance in patients with alcohol dependence (AD) and other substance dependence (SD). We also compared these individuals with healthy volunteers. We hypothesized that AD group had more distress intolerance levels and dysfunctional metacognitive styles than SD group and both of these groups had more distress intolerance and dysfunctional metacognitive styles than healthy volunteers.

\section{Patients and Methods}

\subsection{Participants}

A total of 99 patients including 45 with AD and 44 with SD, diagnosed according to DSM IV-TR criteria,) who applied to Bakirkoy Mazhar Osman Psychiatry and Neurological Science Research and Training Hospital Addiction Outpatient Clinic were enrolled. The mean age was 42.7 \pm 9.9 years for $\mathrm{AD}$ group and $26.6 \pm 4.4$ years for $\mathrm{SD}$. The comparison sample comprised of 43 participants without $\mathrm{AD}$ and $\mathrm{SD}$ with the mean age of $34.4 \pm 12.7$ years.

\subsection{Measures}

Socio-demographic information form, developed by our department for determining age, sex, education level, etc., was used to collect basic characteristics of the participants.

Metacognitions questionnaire-30 (MCQ-30) (24) measures different domains of metacognitions on five separate subscales and consists of 30 items. The five subscales are as follows: 1) Positive beliefs about repetitive thinking, e.g. “Worrying helps me cope”; 2) Negative beliefs about repetitive thinking concerning uncontrollability and danger, e.g. "When I start worrying, I can't stop"; 3) Low cognitive confidence, e.g. "I have a poor memory"; 4) Need to control thoughts, e.g. "I am weak because I can't control my thoughts"; 5) Cognitive selfconsciousness, e.g. "I am conscious about the way that my mind works".

The MCQ-30 and its subscales have good to excellent internal consistency with Cronbach's alpha of 0.93 for total scores and 0.72 to 0.92 for subscales. The overall Kaiser-Meyer-Olkin (KMO) measure for MCQ-30 is 0.90 and the exploratory factor analysis supported a five-factor solution. These five-factors explain $68 \%$ of the variance. The MCQ-30 total scores have strong association with both pathologic worry
(Penn State Worry Questionnaire) and trait-anxiety (Trait Anxiety Inventory) with $r=0.54$ and $r=0.53$, respectively ( $P$ $<0.0005$ ), and shows strong convergent validity (24).

Distress tolerance scale (DTS) (25) measures different domains of distress response on four separate subscales and consists of 15 items. The four subscales of DTS are as follows: 1) Tolerance, e.g. "It is impossible for me to be with my distressing thoughts"); 2) Appraisal, e.g., "Being distressed is unbearable for me"; 3) Absorption, e.g. "When I feel distressed I can't think anything except"; 4) Regulation, e.g. "There is nothing to do when I feel distressed". Higher scores indicate better distress tolerance. The DTS has high internal consistency (Cronbach's alpha, 0.89) and appropriate convergence with other self-report ratings of affective distress and regulation. The scale also has adequate test-retest reliability after six months (25).

\subsection{Procedure}

Ethics approval for the study was obtained from our hospital's ethical committee. A written informed consent form was taken from each participant. Participation in the research project was voluntary. Participants were given writing instructions for answering the questionnaires. Participants completed the socio-demographic information form, MCQ-30, and DTS once.

\section{Results}

There was no significant difference between three groups in MCQ-30 total scores. Regarding five dimensions of MCQ-30, individuals with AD and SD had significantly higher scores in the "positive beliefs" subscale than control group $(\mathrm{U}=702.0$ and $\mathrm{P}=0.012$ for $\mathrm{AD}$ group; $\mathrm{U}=532.0$ and $\mathrm{P}=0.001$, for SD group). In "belief about need to control thoughts" subscale of MCQ-30, individuals with $\mathrm{AD}$ and $\mathrm{SD}$ had higher scores than control group; however, this difference was not statistically significant. We found no significant difference in other subscales of MCQ-30 (Table 1).

Kruskal-Wallis test was used to see whether there was a significant difference between three groups in DTS total scores $\left(\chi^{2}=6.281, P=0.001\right)$. Then Mann-Whitney U-tests were used to determine which group had significant difference with others. Regarding DTS total scores, individuals with SD and control group had significantly higher scores than individuals with $\mathrm{AD}(\mathrm{U}=667.5$ and $\mathrm{P}=0.008$ for $\mathrm{SD}$ sample; $\mathrm{U}=643.5$ and $\mathrm{P}=0.004$ for control group). There was no significant difference between individuals with SD and control group in DTS total scores (Table 2).

Control and SD groups had significantly higher scores in the "tolerance" subscale of DTS than AD group $(\mathrm{U}=$ 583.5 and $\mathrm{P}=0.001$ for community sample; $\mathrm{U}=649.5$ and $\mathrm{P}=0.005$ for SD sample); SD group had significantly higher scores in the "appraisal" subscale of DTS than control $\operatorname{group}(\mathrm{U}=568.0, \mathrm{P}=0.005)$. 
Table 1. Total and Subscale Scores of Metacognitive Questionaire-30 of Alcohol Dependence Group, Substance Dependence Group, and Community Sample ${ }^{\text {a }}$

\begin{tabular}{|c|c|c|c|c|c|c|}
\hline MCQ-30 & No. & Mean of Ranks & Sum of Ranks & Mann-Whitney U & $\mathbf{Z}$ & P Value \\
\hline \multicolumn{7}{|c|}{ MCQ-30 Total scores } \\
\hline $\mathrm{AD}$ & 45 & 48.24 & 2171.00 & 709.000 & -1.922 & 0.065 \\
\hline CS & 41 & 38.29 & 1570.00 & & & \\
\hline SD & 43 & 46.03 & 1979.00 & 729.500 & -1.361 & 0.173 \\
\hline CS & 41 & 38.79 & 1590.00 & & & \\
\hline $\mathrm{AD}$ & 45 & 46.56 & 2095.00 & 875.000 & -0.773 & 0.440 \\
\hline SD & 43 & 42.35 & 1821.00 & & & \\
\hline \multicolumn{7}{|c|}{ Positive beliefs } \\
\hline $\mathrm{AD}$ & 45 & 52.40 & 2358.00 & 702.000 & -2.515 & 0.012 \\
\hline CS & 45 & 38.60 & 1737.00 & & & \\
\hline SD & 44 & 55.41 & 2438.00 & 532.000 & -3.773 & $<0.001$ \\
\hline CS & 45 & 34.82 & 1567.00 & & & \\
\hline $\mathrm{AD}$ & 45 & 42.68 & 1920.50 & 885.500 & -0.861 & 0.389 \\
\hline SD & 44 & 47.38 & 2084.50 & & & \\
\hline \multicolumn{7}{|c|}{ Cognitive confidence } \\
\hline $\mathrm{AD}$ & 45 & 44.44 & 2000.00 & 965.000 & -0.206 & 0.837 \\
\hline CS & 44 & 45.57 & 2005.00 & & & \\
\hline SD & 44 & 44.16 & 1943.00 & 953.000 & -0.126 & 0.900 \\
\hline CS & 44 & 44.84 & 1973.00 & & & \\
\hline $\mathrm{AD}$ & 45 & 44.84 & 2018.00 & 983.000 & -0.058 & 0.954 \\
\hline SD & 44 & 45.56 & 1997.00 & & & \\
\hline \multicolumn{7}{|c|}{ Uncontrollability danger } \\
\hline $\mathrm{AD}$ & 45 & 47.58 & 2141.00 & 829.000 & -1.160 & 0.246 \\
\hline CS & 43 & 41.28 & 1775.00 & & & \\
\hline SD & 44 & 42.63 & 1875.50 & 885.500 & -0.517 & 0.605 \\
\hline CS & 43 & 45.41 & 1952.50 & & & \\
\hline $\mathrm{AD}$ & 45 & 49.50 & 2227.50 & 787.500 & -1.667 & 0.095 \\
\hline SD & 44 & 40.40 & 1777.50 & & & \\
\hline \multicolumn{7}{|c|}{ Cognitive consciousness } \\
\hline $\mathrm{AD}$ & 45 & 50.27 & 2262.00 & 798.000 & -1.740 & 0.082 \\
\hline CS & 45 & 40.73 & 1833.00 & & & \\
\hline SD & 40 & 50.30 & 2010.50 & 959.500 & -0.251 & 0.801 \\
\hline CS & 44 & 35.41 & 1994.50 & & & \\
\hline $\mathrm{AD}$ & 45 & 48.73 & 2193.00 & 822.000 & -1.385 & 0.166 \\
\hline SD & 44 & 41.18 & 1812.00 & & & \\
\hline \multicolumn{7}{|c|}{ Need to control thoughts } \\
\hline $\mathrm{AD}$ & 45 & 50.19 & 2258.50 & 756.500 & -1.922 & 0.055 \\
\hline CS & 44 & 39.69 & 1746.50 & & & \\
\hline SD & 43 & 49.62 & 2133.50 & 704.500 & -2.058 & 0.040 \\
\hline CS & 44 & 38.51 & 1694.50 & & & \\
\hline $\mathrm{AD}$ & 45 & 45.56 & 2050.00 & 920.000 & -0.398 & 0.641 \\
\hline SD & 43 & 43.40 & 1866.00 & & & \\
\hline
\end{tabular}

a Abbreviation: AD, alcohol dependence; CS, community sample; MCQ-30, metacognitive questionaire-30; and SD, substance dependence. 
Ipek OU et al.

Table 2. Total and Subscale Scores of Distress Tolerance Scale in Alcohol Dependence Group, Substance Dependence Group, and Community Sample ${ }^{\mathrm{a}}$

\begin{tabular}{|c|c|c|c|c|c|c|}
\hline DTS & No. & Mean of Ranks & Sum of Ranks & Mann-Whitney U & $\mathbf{Z}$ & PValue \\
\hline \multicolumn{7}{|c|}{ Total scores } \\
\hline $\mathrm{AD}$ & 45 & 35.97 & 1618.50 & 643.500 & -2.854 & 0.004 \\
\hline CS & 44 & 54.24 & 2386.50 & & & \\
\hline SD & 44 & 44.52 & 1959.00 & 967.000 & -0.008 & 0.993 \\
\hline CS & 44 & 44.48 & 1957.00 & & & \\
\hline $\mathrm{AD}$ & 45 & 37.83 & 1702.50 & 667.500 & -2.648 & 0.008 \\
\hline SD & 44 & 52.33 & 2302.50 & & & \\
\hline \multicolumn{7}{|c|}{ Tolerance } \\
\hline $\mathrm{AD}$ & 45 & 35.07 & 1618.50 & 583.500 & -3.340 & 0.001 \\
\hline CS & 44 & 54.24 & 2386.50 & & & \\
\hline SD & 44 & 43.20 & 1901.00 & 911.000 & -0.476 & 0.634 \\
\hline CS & 44 & 45.80 & 2015.00 & & & \\
\hline $\mathrm{AD}$ & 45 & 37.43 & 1684.50 & 649.500 & -2.797 & 0.005 \\
\hline SD & 44 & 52.74 & 2320.50 & & & \\
\hline \multicolumn{7}{|c|}{ Regulation } \\
\hline $\mathrm{AD}$ & 45 & 40.34 & 1815.50 & 780.500 & 1.883 & 0.060 \\
\hline CS & 45 & 50.66 & 2279.50 & & & \\
\hline SD & 44 & 44.39 & 1953.00 & 963.000 & -0.223 & 0.823 \\
\hline CS & 45 & 45.60 & 2052.00 & & & \\
\hline $\mathrm{AD}$ & 45 & 40.72 & 1832.50 & 797.500 & -1.588 & 0.112 \\
\hline SD & 44 & 49.38 & 2172.50 & & & \\
\hline \multicolumn{7}{|c|}{ Appraisal } \\
\hline $\mathrm{AD}$ & 28 & 42.05 & 1177.50 & 460.500 & -1.810 & 0.070 \\
\hline CS & 44 & 32.97 & 1450.50 & & & \\
\hline SD & 40 & 50.30 & 2012.00 & 568.000 & -2.813 & 0.005 \\
\hline CS & 44 & 35.41 & 1558.00 & & & \\
\hline $\mathrm{AD}$ & 28 & 37.83 & 1702.50 & 512.000 & -0.604 & 0.546 \\
\hline SD & 40 & 52.33 & 2302.50 & & & \\
\hline
\end{tabular}

a Abbreviation: DTS, distress tolerance scale; AD, alcohol dependence; SD, substance dependence; and CS, community sample.

\section{Discussion}

Our work was probably the first study that compared metacognitions and distress tolerance in patients with $\mathrm{AD}$ and other SD. Although some researches focused on metacognitions with problem drinking and substance use $(8,20-23)$, their samples consisted of participants with both AD and SD.

In the "positive beliefs" subscale of MCQ-30, results of present study showed that AD and SD groups had significantly higher scores than control group. Moreover, in "belief about need to control thoughts" subscale of MCQ-30, individuals with AD and SD had higher than scores than control group, with no significant difference. These findings are consistent with research results of Spada et al. (26) and Saed et al. (23). According to the metacognitive theory, individuals with addictive behaviors may worry or ruminate about triggers based on their positive metacognitive beliefs and this process leads to increased negative thoughts and emotions (9). These increased inter- nal events can evoke the maladaptive coping behaviors such as suppression based on their existent beliefs about "need to control thoughts". We know that positive metacognitive beliefs can affect drinking alcohol in order to regulate cognition and emotion (21). In our study, other subscales of MCQ-30 had no significant difference with previous researches. This inconsistency can be explained by our small sample size. Another possible explanation can be the existing psychologic disorders in our control group. As we know that dysfunctional metacognitive styles have been found to be related to psychologic disorders and our participants did not complete any scale to exclude other psychologic disorders (13-19, 27). Therefore, other psychologic disorders might have raised MCQ-30 subscales in controls.

We found no significant differences between individuals with $\mathrm{AD}$ and SD in metacognitive subscales. This finding shows that all of the patients with long-term alcohol 
and substance use maintain higher metacognitive patterns such as "positive metacognitive beliefs" and did not have any healer effect on these beliefs.

In addition to researches on $\mathrm{AD}$, we could not find any study focused on metacognitions in those with only SD. We hypothesized that in contrast to $\mathrm{AD}$, individuals with SD have less distress intolerance than control group. Our results have shown that $A D$ group had significantly lower scores in the DTS and "tolerance" subscale than SD group. "Tolerance" subscale of DTS focuses on individuals' relation with distress and lower scores means intolerance of distress. According to our findings, we can conclude that individuals keep on alcohol use due to negative reinforcement. This is consistent with some researches that found associations between $\mathrm{AD}$ and emotional regulation $(28,29)$.

In contrast to $\mathrm{AD}$, our results did not support the importance of emotion regulation processes in SD. It can be concluded that substance use may work through positive reinforcement rather than emotional regulation strategy as a negative reinforcement. Regarding our findings, we can suggest more focus on emotional acceptance interventions for $\mathrm{AD}$ and more focus on values and long-term goalsrelated interventions for SD during treatment process.

One limitation in our research was the small sample size for drawing certain conclusions. The lack of significant difference in MCQ-30 subscales between AD and SD groups may be about small size of our sample. Another one is about our study design. Because of descriptive and retrospective design, there is a need for longitudinal more valid trials to explore metacognitive processes of individuals with $\mathrm{AD}$ and $\mathrm{SD}$. In addition, we did not include healthy volunteers to our study for examining the difference in psychologic disorders from healthy subjects. Lack of this data may be important for evaluations of our results.

Present study may suggest that in SD, cognitive regulation strategies are more common than emotional regulation strategies, which discriminates SD from AD. Individuals with $\mathrm{AD}$ use alcohol as a means of both cognitive and emotional regulation strategy.

\section{Authors' Contributions}

Okan Ufuk Ipek: Collection of data, analysis, interpretation of results, and writing the draft; Kaasim Fatih Yavuz and Sevinc Ulusoy: Research conception and design, revision of the manuscript, analysis, and interpretation of results; Oktay Sahin: Data collection of data; Erhan Kurt: Revision of the manuscript.

\section{References}

1. Helzer JE, Pryzbeck TR. The co-occurrence of alcoholism with other psychiatric disorders in the general population and its impact on treatment. J Stud Alcohol.1988;49(3):219-24.

2. Kushner MG, Sher KJ, Beitman BD. The relation between alcohol problems and the anxiety disorders. Am J Psychiatry.
1990;147(6):685-95.

3. Wilson GT. Alcohol and anxiety. Behav Res Ther. 1988;26(5):369-81.

4. Conger JJ. Alcoholism: theory, problem and challenge. II. Reinforcement theory and the dynamics of alcoholism. QJ Stud Alcohol.1956;17(2):296-305.

5. Duncan DF. Letter: Drug abuse as a coping mechanism. Am J Psychiatry. 1974;131(6):724.

6. Levenson RW, Sher KJ, Grossman LM, Newman J, Newlin DB. Alcohol and stress response dampening: pharmacological effects, expectancy, and tension reduction. J Abnorm Psychol. 1980;89(4):528-38.

7. Monti PM. Treating Alcohol Dependence: A Coping Skills Training Guide.New York: Guilford Press; 2002.

8. Toneatto T. Metacognition and substance use. Addict Behav. 1999;24(2):167-74.

9. Wells A. Emotional Disorders and Metacognition: Innovative Cognitive Therapy.Chichester, UK: Wiley; 2002.

10. Wells A, Matthews G. Attention and Emotion: A Clinical Perspective.New York: Taylor \& Francis Group; 1994.

11. Wells A, Matthews G. Modelling cognition in emotional disorder: the S-REF model. Behav Res Ther.1996;34(11-12):881-8.

12. Spaite DW, Meislin HW, Valenzuela TD, Criss EA, Smith R, Nelson A. Banning alcohol in a major college stadium: impact on the incidence and patterns of injury and illness. J Am Coll Health. 1990;39(3):125-8.

13. Papageorgiou C, Wells A. An empirical test of a clinical metacognitive model of rumination and depression. Cognit Ther Res. 2003;27(3):261-73.

14. Fernie BA, Spada MM. Metacognitions about procrastination: A preliminary investigation. Behav Cogn Psychother. 2008;36(03):359-64.

15. Wells A, Papageorgiou C. Relationships between worry, obsessive-compulsive symptoms and meta-cognitive beliefs. Behav Res Ther.1998;36(9):899-913.

16. Spada MM, Nikcevic AV, Moneta GB, Wells A. Metacognition, perceived stress, and negative emotion. Pers Individ Dif. 2008;44(5):1172-81.

17. Bouman TK, Meijer KJ. A preliminary study of worry and metacognitions in hypochondriasis. Clin Psychol and Psychother. 1999;6(2):96-101.

18. Roussis P, Wells A. Post-traumatic stress symptoms: Tests of relationships with thought control strategies and beliefs as predicted by the metacognitive model. Pers Individ Dif. 2006;40(1):111-22.

19. Spada MM, Nikcevic AV, Moneta GB, Ireson J. Metacognition as a mediator of the effect of test anxiety on a surface approach to studying. Educ Psychol. 2006;26(5):615-24.

20. Spada MM, Wells A. Metacognitions, emotion and alcohol use. Clin Psychol Psychother. 2005;12(2):150-5.

21. Spada MM, Wells A. Metacognitive beliefs about alcohol use: development and validation of two self-report scales. Addict Behav. 2008;33(4):515-27.

22. Spada MM, Caselli G, Wells A. Metacognitions as a predictor of drinking status and level of alcohol use following CBT in problem drinkers: a prospective study. Behav Res Ther. 2009;47(10):882-6.

23. Saed O, Yaghubi H, Roshan R. The role of Meta-cognitive beliefs on substance dependency. Procedia Soc Behav Sci. 2010;5:1676-80.

24. Wells A, Cartwright-Hatton S. A short form of the metacognitions questionnaire: properties of the MCQ-30. Behav Res Ther. 2004;42(4):385-96.

25. Simons JS, Gaher RM. The Distress Tolerance Scale: Development and validation of a self-report measure. Motiv. 2005;29(2):83-102.

26. Spada MM, Zandvoort M, Wells A. Metacognitions in problem drinkers. Cogn Ther Res. 2007;31(5):709-16.

27. Cartwright-Hatton S, Wells A. Beliefs about worry and intrusions: the Meta-Cognitions Questionnaire and its correlates. J Anxiety Disord. 1997;11(3):279-96.

28. Lazarus RS. Cognition and motivation in emotion. Am Psychol. 1991;46(4):352-67.

29. Carey KB, Correia CJ. Drinking motives predict alcohol-related problems in college students. J Stud Alcohol.1997;58(1):100-5. 